\title{
REGIÕES METROPOLITANAS NO BRASIL: REGIME JURÍDICO E ESTRUTURA DE GOVERNANÇA
}

\begin{abstract}
Dissertação apresentada à Banca Examinadora do Programa de Pós-Graduação em Direito, da Faculdade de Direito da Universidade de São Paulo, como exigência parcial para obtenção do título de Mestre em Direito, na área de concentração em Direito do Estado, sob a orientação do Prof. Dr. Dalmo de Abreu Dallari.
\end{abstract}

\section{UNIVERSIDADE DE SÃO PAULO}

\section{FACULDADE DE DIREITO}

São Paulo - SP 
Catalogação da Publicação

Serviço de Biblioteca e Documentação

Faculdade de Direito da Universidade de São Paulo

Santos, Marcela de Oliveira

Regiốes Metropolitanas no Brasil: regime jurídico e estrutura de governança / Marcela de Oliveira Santos ; orientador Dalmo de Abreu Dallari -- São Paulo, 2017.

$168 \mathrm{p}$.

Dissertação (Mestrado - Programa de Pós-Graduação em Direito do Estado) - Faculdade de Direito, Universidade de São Paulo, 2017.

1. Regiões metropolitanas. 2. Estatuto da Metrópole. 3. Regime juridico. 4. Estrutura de governança. 5. Organização administrativa. I. Dallari, Dalmo de Abreu, orient. II. Título. 
Nome: SANTOS, Marcela de Oliveira.

Título: Regiões Metropolitanas no Brasil: Regime Jurídico e Estrutura de Governança

Dissertação apresentada à Banca Examinadora do Programa de Pós-Graduação em Direito, da Faculdade de Direito da Universidade de São Paulo, como exigência parcial para obtenção do título de Mestre em Direito, na área de concentração em Direito do Estado.

Orientador: Prof. Dr. Dalmo de Abreu Dallari.

Aprovada em: de de

\section{BANCA EXAMINADORA}

Prof. Dr. Dalmo de Abreu Dallari (Orientador)

Assinatura:

Prof. Dr. Fabrício Macedo Motta

Assinatura:

Profa. Dra. Daniela Campos Libório

Assinatura:

Prof. Dr. Marcos Augusto Perez

Assinatura:
Instituição: FDUSDP

Julgamento:

Instituição: UFG

Julgamento:

Instituição: PUC-SP

Julgamento:

Instituição: FDUSP

Julgamento: 



\section{AGRADECIMENTOS}

Este não foi um sonho que sonhei só: foi sonho repleto de companheirismo, amizade, compreensão e outros sonhos. Há muito que a vida me tem sido bastante generosa, colocando no meu caminho pessoas incríveis e inspiradoras.

Agradeço aos pais maravilhosos que deus me deu, Suelânia e Reiner, que se esforçaram todos os dias para que nunca faltasse amor e livros em nosso lar e que sempre me apoiaram incondicionalmente, mesmo nas aventuras "insaciáveis" que escolhi viver. Ao meu querido maninho, Reiner Ricardo, que tem a ímpar capacidade de me tornar um ser humano melhor em cada diálogo cotidiano. Meu obrigada a todos os meus familiares que sempre me incentivaram a perseguir os meus sonhos.

Sinto-me privilegiada por ter a oportunidade de enfrentar tamanho desafio sob a orientação de Dalmo de Abreu Dallari, ser humano e jurista de valor imensurável, guerreiro combatente na luta pela democracia e por um Estado justo. Ao meu Mestre (e aqui esta palavra detém mais força que a titulação de "Doutor") e ilustre professor, agradeço pelas reflexões que seus textos me provocaram, desde os tempos da graduação, e especialmente por esses três anos de árduo trabalho, sempre próximo e atencioso.

Agradeço à banca do exame de qualificação, composta por meu orientador, pelo Professor Doutor Rodrigo Pagani e pelo Professor Marcos Augusto Perez, pelas valiosas críticas e por terem me ajudado a encontrar a luz que faltava ao trabalho.

Aos membros da banca de defesa, Professor Doutor Marcos Augusto Perez, Professora Doutora Daniela Campos Libório e Professor Doutor Fabrício Motta, por terem aceitado o convite para me colocarem à prova depois de tanto esforço e dedicação e pelas ideias e trabalhos que me subsidiaram na construção da dissertação.

Aos meus sócios do CMS Advogados, Wladimyr Camargos, Heloísa Melo e Luene Santos, pela paciência e pela barra que me ajudaram a segurar ao longo deste ano.

Aos presentes em forma de pessoas que a USP me deu. Foram muitas as pessoas especiais, às quais agradeço em nome de Anna Beatriz Savioli, Bruno Fagali, Letícia Alencar, Natália Rebello, José Antônio Apparecido Júnior.

Fernando Couto Garcia, companheiro de direito urbanístico, merece agradecimento destacado, pelas intermináveis discussões, pela indicação de bibliografia e pela revisão minuciosa que resultou em significativa melhoria no trabalho. 

Agradeço aos colegas e aos sócios do escritório Manesco, Ramires, Perez, Azevedo Marques, o qual me acolheu em São Paulo e me ajudou a transformar essa cidade em lar.

Foi dali que surgiu o interesse pelo tema de regiões metropolitanas, a partir dos trabalhos e conversas com Wladimir António Ribeiro, mestre e amigo com quem brindei a existência - e as metrópoles - inúmeras vezes.

Dali também fui presenteada com a fiel amizade de Marina Fontão Zago, minha fonte de inspiração para os momentos difíceis.

Agradeço ao amigo Daniel Salomoni, por todos os debates sobre o tema e pela entrevista concedida acerca da Região Metropolitana de Salvador.

A Hendrick Pinheiro, que me adoçava o cotidiano no trabalho e que segue me estimulando a alçar voos.

Agradeço a Raquel Lamblogia pelo dia a dia de "sofrência" e alegria em diversas etapas da dissertação e da vida.

Meu obrigada a Fabrício Muriana, por me apresentar sempre uma nova São Paulo, pela leitura do texto da qualificação e pelas constantes conversas sobre ser e estar em uma cidade.

À goianidade e aos queridos amigos de Goiânia, da legião dos Advândalos, com quem aprendo todos os dias que sem justiça, não há direito. Sem esses amigos, com quem tenho o privilégio de partilhar minhas inquietações sobre a vida, o universo e tudo mais, o caminho até aqui não teria sentido. Agradeço especialmente à Ana Luiza Krüger, pela cuidadosa revisão, que aprimorou em muito o texto.

No meu amado Goiás também preciso agradecer aos professores e colegas da Universidade Federal de Goiás, especialmente a Fabrício Motta, que foi o responsável pelo primeiro brilho nos olhos que experimentei com o Direito Administrativo. Desde 2010, sigo admirando o seu trabalho e sua forma de lidar com o mundo. Meu muito obrigada por me estimular o desassossego e a eterna busca por novos desafios.

Agradeço, ainda, aos colegas da Secretaria de Estado de Meio Ambiente, Recursos Hídricos, Infraestrutura, Cidades e Assuntos Metropolitanos (SECIMA-GO), especialmente Marcelo Sáfadi, Juliano Martins Rodrigues, Lucelena Melo, Marcela Ruggeri Meneses e André Freitas, por me permitirem acompanhar de perto o primoroso trabalho que tem sido feito para a gestão da Região Metropolitana de Goiânia. 

Às amigas de alma Ana Carolina Castro e Mariana Mendes Scalzitti, pelo socorro nos momentos de angústia e com quem ando sempre e para sempre de mãos dadas.

Agradeço também à equipe do projeto Governança Metropolitana do Instituto de Pesquisa Econômica Aplicada (IPEA), Marco Aurélio Costa, Bárbara Oliveira Marguti, César Buno Favarão e Sara Rebello Tavares, que, além de me oportunizarem a imersão no tema por ocasião da pesquisa realizada neste ano, me forneceram subsídios e reflexões indispensáveis ao fechamento desta dissertação. 

À minha São Paulo, que diariamente me proporciona a dor e a delícia de viver em uma metrópole. 

"Um bom governo pressupõe duas condições: primeiro, a fidelidade a seu objetivo, que é a felicidade do povo; segundo, um conhecimento dos meios pelos quais o objetivo pode ser melhor atingido".

James Madison, O Federalista, Artigo 62. 



\section{RESUMO}

SANTOS, Marcela de Oliveira. Regiões Metropolitanas no Brasil: regime jurídico e estrutura de governança. 2017. 180 p. Mestrado - Faculdade de Direito, Universidade de São Paulo, São Paulo, 2017.

O presente trabalho propõe-se a estudar as regiões metropolitanas tomadas enquanto instituto jurídico, investigando o seu regime jurídico após a edição de novo marco legal e propondo caminhos para a construção de um "sistema metropolitano". Para a realização dessa tarefa, inicia-se caracterizando o processo de institucionalização das regiões metropolitanas no Brasil em quatro diferentes fases, desde a década de 60 (primeiro marco), passando pela Constituição de 1988 e décadas seguintes (segundo marco), até a história mais recente, quando o Supremo Tribunal Federal, após quase quinze anos, profere acórdão na Ação Direta de Inconstitucionalidade 1.842/RJ (terceiro marco) e considerando a edição da Lei $\mathrm{n}^{\circ}$ 13.089/2015, que instituiu o Estatuto da Metrópole (quarta fase). Realiza-se, a seguir, o estudo minucioso do regime jurídico aplicável a tais entidades, trazendo reflexões e propondo interpretações acerca dos pontos mais polêmicos da questão metropolitana, em especial: a leitura das regiões metropolitanas como instrumentos de cooperação federativa e de promoção de políticas públicas; a harmonia jurídica entre a criação de regiões metropolitanas e a autonomia municipal; a definição legal e jurídica da região metropolitana como uma conciliação entre o fenômeno urbanístico de metropolização e a criação das unidades regionais; os limites da atuação legislativa do Estado; o papel central do plano de desenvolvimento urbano integrado. Em seguida, analisa-se as possibilidades jurídicas de conformação da estrutura de governança e sua organização administrativa, apresentando as atribuições e características jurídicas necessárias à gestão metropolitana e comparando as figuras dos órgãos, autarquias, empresas públicas e sociedades de economia mista como estruturas integradoras das funções públicas de interesse comum. Conclui-se que não existe um modelo único e ideal que possa ser adotado em todas as regiões metropolitanas, mas propõe-se que as atribuições mínimas estejam presentes em qualquer modelo escolhido. Finaliza-se sugerindo limites de conteúdo da lei complementar estadual e propondo a criação de um sistema metropolitano com a conjugação de vários modelos jurídicos.

Palavras-chave: Regiões metropolitanas. Estatuto da Metrópole. Regime jurídico. Estrutura de governança. Organização administrativa. 



\begin{abstract}
SANTOS, Marcela de Oliveira. Metropolitan Regions in Brazil: legal regime and governance structure. 2017. 180 p. Master - Faculty of Law, University of São Paulo, São Paulo, 2017.

This work proposes to study the metropolitan regions as a legal institute, investigating its legal regime after the edition of a new legal framework and suggesting ways of building a "metropolitan system". In order to do so, we begin by characterizing the process of institutionalization of the metropolitan regions in Brazil in four different phases, since the 1960s (first phase), passing through the 1988 Constitution and following decades (second phase), until the more recent history, when the Federal Court of Justice, after almost fifteen years, pronounces the judgement in the Direct Action of Unconstitutionality 1.842/RJ (third phase) and considering the edition the Law ${ }^{\circ} 13.089 / 2015$, which institutes the Statute of the Metropolis (fourth phase).Next, we conduct a thorough study of the legal regime that can be applicable to such entities, reflecting and suggesting interpretations about the most controversial aspects of the metropolitan issue, specially: the comprehension of the metropolitan regions as instruments of federative cooperation and promotion of public policies; the legal harmony between the creation of metropolitan regions and municipal autonomy; the legal definition of metropolitan regions as a conciliation between the urban phenomenon of metropolization and the creation of regional units; the limits of the legislative activity of the State; the central role of the integrated urban development plan. Then, we analyze the legal possibilities of conforming the governance structure and its administrative organization, presenting the attributions and legal characteristics necessary to the metropolitan management, and comparing the configuration of agencies, autarchies, public companies and joint capital companies as possibilities of integrative structures of public functions of common interest. We conclude that there is not a unique and ideal model that can be adopted in all metropolitan regions, but we propose that the minimal attributions must be present in any chosen model. We finish the work suggesting limits in the content of the state complementary law and proposing the creation of a metropolitan system conjugating various legal models.
\end{abstract}

Keywords: Metropolitan Regions. Statute of the Metropolis. Legal Regime. Governance Structure. Administrative Organization. 



\section{LISTA DE ABREVIATURAS}

ADI

$\mathrm{BNH}$

BRDES

CAF

CASAN

$\mathrm{CF}$

CNPU

COMEC

ConCidades

CONDEPE/FIDEM

DIRUR

EC

EMPLASA

FGTS

FNDU

FPIC

IBGE

IJSN

INE

IPEA

IPs

LC

METROPLAN

PAC

PDUI

PL

PLANASA

PLS

PND

PNLP

PNLT
Ação Direta de Inconstitucionalidade

Banco Nacional de Habitação

Banco Regional de Desenvolvimento do Estremo Sul

Comitê de Articulação e Pactuação Federativa

Companhia Catarinense de Águas e Saneamento

Constituição Federal

Comissão Nacional de Regiões Metropolitanas e Política Urbana

Coordenação da Região Metropolitana de Salvador

Conselho Nacional das Cidades

Agência Estadual de Planejamento e Pesquisa de Pernambuco

Diretoria de Estudos e Políticas Regionais, Urbanas e Ambientais

Emenda Constitucional

Empresa Paulista de Planejamento Metropolitano

Fundo de Garantia do Tempo de Serviço

Fundo Nacional de Desenvolvimento Urbano

Funções Públicas de Interesse Comum

Instituto Brasileiro de Geografia e Estatística

Instituto Jones dos Santos Neves

Instituto Nacional de Estatística

Instituto de Pesquisa Econômica Aplicada

Instituições Participativas

Lei Complementar

Fundação Estadual de Planejamento Metropolitano Regional da

Região Metropolitana de Porto Alegre

Programa de Aceleração do Crescimento

Plano de Desenvolvimento Urbano Integrado

Projeto de Lei

Plano Nacional de Saneamento Básico

Projeto de Lei do Senado

Plano Nacional de Desenvolvimento

Plano Nacional de Logística Portuária

Plano Nacional de Logística em Transporte 

PPPs

$\mathrm{RE}$

REGIC

RIDE/DF

$\mathrm{RM}$

SERFHAU

STF

SUDERF
Parcerias Público-Privadas

Recurso Extraordinário

Regiões de Influência das Cidades

Região Integrada de Desenvolvimento do Distrito Federal e Entorno Região Metropolitana

Serviço Federal de Habitação e Urbanismo

Supremo Tribunal Federal

Superintendência de Desenvolvimento da Região Metropolitana da Grande Florianópolis 



\section{SUMÁRIO}

INTRODUÇÃO

\section{A EVOLUÇÃO DA INSTITUCIONALIZAÇÃO DAS REGIÕES METROPOLITANAS NO BRASIL: EM BUSCA DE UM REGIME JURÍDICO .... 30}

1.1 O processo de institucionalização como elemento de fundo da "questão metropolitana".

1.2 Das primeiras metrópoles à década de 80: centralização na União e ausência de cooperação entre os entes.

1.3 As regiões metropolitanas na Constituição de 1988: a emancipação municipal e o esvaziamento das regiões metropolitanas

1.4 As transformações na Administração Pública, as mudanças constitucionais e a ADI 1.842/RJ: novos parâmetros normativos para institucionalização das regiões metropolitanas

1.5 O novo marco legal - Lei $n^{\circ}$ 13.089/2015 (Estatuto da Metrópole): suficiência dos parâmetros normativos para institucionalização e definição do regime jurídico .52

2 REGIME JURÍDICO DAS REGIÕES METROPOLITANAS .57

2.1 O federalismo cooperativo e as regiões metropolitanas: harmonia necessária para a gestão adequada

2.2 Interface entre interesse local, interesse metropolitano e interesse comum: o interesse comum como fundamento da integração

2.3 Nem do Estado, nem dos Municípios: a titularidade das funções públicas de interesse comum é do colegiado formado pelos entes

2.4 A finalidade da instituição da região metropolitana: integrar a organização, o planejamento e a execução das funções públicas de interesse comum....

2.5 Da metrópole àregião metropolitana: o conceito jurídico de região metropolitana... 82

2.6 A lei complementar estadual instituidora da região metropolitana: conteúdo, iniciativa e limites ao exercício da competência legislativa 88

2.7 A compulsoriedade da integração dos Municípios na região metropolitana em equilíbrio com a autonomia municipal.

2.8 O planejamento nas regiões metropolitanas: o plano de desenvolvimento urbano integrado (PDUI) e compatibilização com demais planos 


\section{ESTRUTURA DE GOVERNANÇA E ORGANIZAÇÃO ADMINISTRATIVA}

PARA INTEGRAÇÃO DAS FUNÇÕES PÚBLICAS DE INTERESSE COMUM .. 109

3.1 A "estrutura de governança" não necessariamente corresponde à "organização administrativa" integradora das FPICs

3.2 Parâmetros constitucionais, legais e jurisprudenciais para a conformação da estrutura de governança visando à integração das FPICs......................................................... 111

3.3 A gestão democrática e a obrigatoriedade de representação da sociedade civil na estrutura de governança da região metropolitana...................................................... 120

3.4 A personalidade jurídica da estrutura como pressuposto para a integração das FPICs 126

3.5 Competências e atribuições da estrutura institucional integradora das FPICs ..........131

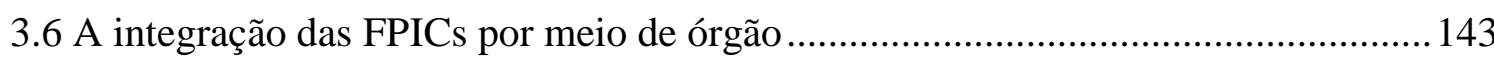

3.7 A integração das FPICs por meio de autarquia .................................................... 146

3.8 A integração das FPICs por meio de arranjos empresariais - sociedade de economia

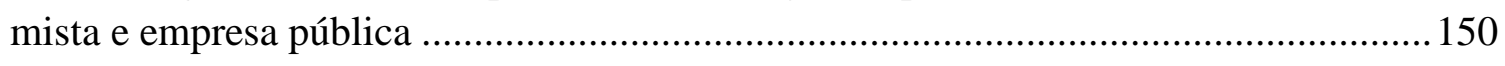

3.9 Consórcio público como instrumento de desenvolvimento urbano integrado ...........155

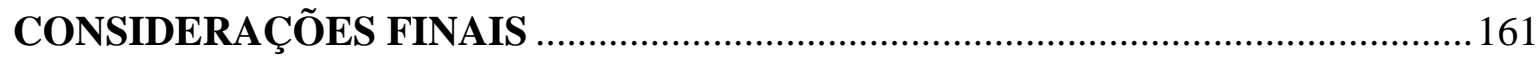

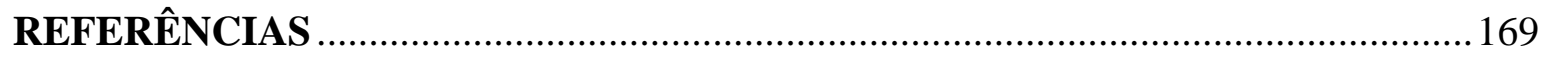




\section{INTRODUÇÃO}

Segundo o último Censo do IBGE (2010), mais da metade da população brasileira reside em áreas metropolitanas ${ }^{1}$. As "metrópoles" representam um fenômeno independente e anterior ao Direito. A metropolização é um processo histórico, de facetas socioeconômicas e geográficas, que parte da urbanização, a qual, cada vez mais intensa, resulta na formação de uma mancha urbana, com a consolidação de relações de interdependência entre os territórios envolvidos (conurbação) ${ }^{2}$.

É na complexidade urbana que as necessidades públicas vão se manifestar em larga escala, ensejando a atuação da Administração Pública nestes territórios. A solução dos problemas metropolitanos dificilmente será alcançada por meio de iniciativas isoladas, mas dependerá de articulação e gestão integradas por todas as instituições e pessoas atuantes nos territórios envolvidos e da criação de estruturas institucionais propícias à integração.

O fenômeno metropolitano pode ser analisado na perspectiva fática-urbanística, enquanto realidade urbana, econômica e social, ou enquanto instituto jurídico ${ }^{3}$. É desse segundo aspecto que cuida a presente pesquisa, que se justifica pela necessidade de se buscar soluções para os paradoxos existentes nesses espaços.

A figura da região metropolitana não é nova entre nós: sua previsão na ordem constitucional brasileira remonta ao final de década de 70 e foi mantida na Constituição Federal de 1988 (art. 25, $\S 3^{\circ}$ ). A doutrina especializada (AZEVEDO \& GUIA, 2000; GOUVÊA, 2001; GRAU, 1974) sedimentou o entendimento segundo o qual o principal problema da gestão metropolitana residia nas lacunas e nas fragilidades de institucionalização das regiões metropolitanas, resultando na ausência de um regime jurídico claro ${ }^{4}$. Após a instituição do

\footnotetext{
${ }^{1}$ Hoje, a taxa de urbanização no país é de $84,36 \%$ (porcentagem da população da área urbana em relação à população total), quase o dobro da taxa de 44,67\% de 1960. Dados extraídos de: Estatísticas do século XX. Rio de Janeiro: IBGE, 2007 no Anuário Estatístico do Brasil, 1981, vol. 42, 1979.

${ }^{2}$ De acordo com Balbim et al. (2012), a expressão "conurbação" teria sido cunhada por Patrick Geddes, em 1915, para descrever o fenômeno de urbanização e metropolização de Londres e das regiões industriais inglesas.

${ }^{3}$ Como esclarece Carlos Bastide Horbach (2004, p. 121), instituto “é a expressão utilizada para designar o conjunto de regras e princípios que regem certas situações de direito, sendo, portanto, um complexo ordenado de normas configurando um todo coerente em torno de uma parte específica de um objeto de um ramo do Direito".

${ }^{4}$ AZEVEDO, Sérgio de; GUIA, Virgínia R. dos Mares. Reforma do Estado e federalismo: os desafios da governança metropolitana. In: RIBEIRO, Luiz César de Queiroz (Coord.). O futuro das metrópoles: desigualdades e governabilidade. Rio de Janeiro: Revan, 2000; GOUVÊA, Ronaldo Guimarães, Autonomia municipal em regiões metropolitanas: as questões administrativa e política. Trabalho apresentado no XXIII International Congress of the Latin American Studies Association LASA 2001. Washington, D.C: 2001. p. 3. Disponível em: <http://lasa.international.pitt.edu/Lasa2001/GuimaraesGouveaRonaldo.pdf>. Acesso em 16 jun. 2016. GRAU, Eros. Regiões metropolitanas: regime jurídico. São Paulo: José Bushatsky, 1974.
} 
Estatuto da Metrópole pela Lei no 13.089 , de 12 de janeiro de 2015, marco legal especificamente direcionado para essas unidades regionais, o cenário jurídico se alterou de maneira significativa.

Diante disso, a presente dissertação se debruça sobre os seguintes problemas: qual é o regime jurídico da região metropolitana em face do Estatuto da Metrópole, conjugado com a Constituição e com sua interpretação pelo Supremo Tribunal Federal, especificamente na Ação Direta de Inconstitucionalidade 1.842/RJ? Definido este regime, quais são os requisitos e características que devem ter a estrutura de governança e a organização administrativa para a adequada integração da organização, o planejamento e a execução das funções públicas em comum nas regiões metropolitanas? Quais são as formas jurídicas possíveis para essa integração? Existe uma forma jurídica considerada ideal para a gestão metropolitana?

Testamos as seguintes hipóteses: do ponto de vista jurídico-institucional, as lacunas de institucionalização foram sendo gradualmente superadas por meio do fortalecimento do marco normativo para tais unidades regionais, cuja última expressão é o Estatuto da Metrópole; do marco legal, é possível extrair um regime jurídico bem delineado; a Constituição e o Estatuto da Metrópole direcionam o legislador estadual à criação de estrutura jurídica integradora; não existe um modelo único de estrutura aplicável a todas as regiões metropolitanas.

Pretendemos sustentar que existem parâmetros mínimos que devem estar presentes na estruturação de qualquer dos modelos jurídicos de região metropolitana. Assim, a construção de um "sistema metropolitano", com a conjugação de diferentes estruturas administrativas, apresenta-se como o caminho mais adequado para a integração das funções públicas de interesse comum.

A identificação do regime jurídico aplicável a tais unidades territoriais não é tarefa fácil, e há muito tempo diversos juristas têm se debruçado sobre a questão. ${ }^{5}$ No centro deste desafio

\footnotetext{
${ }^{5}$ Dentre os estudiosos que se debruçaram com profundidade sobre o tema está Eros Roberto Grau, que publicou, em 1974, o livro "Regiões metropolitanas: Regime jurídico" (São Paulo: José Bushatsky, 1974). Algumas das conclusões ali apresentadas foram revistas pelo próprio autor cerca de dez anos depois, no livro "Direito Urbano: Região Metropolitana, Solo Criado, Zoneamento e Controle Ambiental, Projeto de Lei de Desenvolvimento Urbano" (São Paulo: Revista dos Tribunais, 1983). Alaôr Caffé Alves publicou, em 1981, "Planejamento Metropolitano e Autonomia Municipal” (São Paulo: Baushatsky, 1981). Eurico de Andrade Azevedo também publicou diferentes estudos sobre o assunto. Cf. AZEVEDO, Eurico de Andrade. Instituição das Regiões Metropolitanas no Brasil. Revista Brasileira dos Municípios, Rio de Janeiro, v. 20. n. 79/80, jul-dez/1967. p.121129; AZEVEDO, Eurico de Andrade; MENDES, Raul Armando. Princípios para instituição de regiões metropolitanas. Revista Justitia, v. 57, n. 68, ano XXIX, p.79-97, $2^{\circ}$ trim./1967. Mais recentemente, Ana Carolina Wanderley Teixeira ("Região Metropolitana. Instituição e Gestão Contemporânea - Dimensão Participativa", Belo Horizonte: Fórum, 2009) e Reinaldo Moreira Bruno ("Regiões Metropolitanas: Posição no Cenário Constitucional, Competência e Financiamento de Suas Atividades do Estado Brasileiro", Curitiba: Juruá, 2016) publicaram suas contribuições. O Instituto de Pesquisa Econômica Aplicada - IPEA tem estado à frente de tais discussões, protagonizando debates e estudos sobre as regiões metropolitanas no Brasil. Atualmente, o órgão desenvolve o programa Governança Metropolitana, no qual a autora deste trabalho participou como pesquisadora, elaborando o texto base do livro "Comentários ao Estatuto da Metrópole".
} 
está o delineamento (e a exploração teórica) de um marco normativo específico e bem desenhado das regiões metropolitanas. Para o estudo acerca da estrutura de governança e da organização administrativa dessas unidades regionais, faz-se necessário o resgate da evolução histórica do seu caminho de institucionalização, vis-à-vis o processo de metropolização verificado no país e a trajetória do federalismo nacional, o que será feito no Capítulo 1.

São apresentados quatro diferentes marcos de institucionalização, com a identificação dos elementos essenciais acerca da estrutura institucional metropolitana em cada um: um primeiro, que remonta ao início da urbanização do Brasil, entre as décadas de 1960 e 1980, relacionado ao modelo de gestão centralizador empreendido pela União, durante o Regime Militar; um segundo, do período da Assembleia Constituinte e da Constituição de 1988, marcado pela tônica do municipalismo; um terceiro marco, que pode ser verificado a partir da década de 1990, em que o contexto do federalismo altera profundamente o cenário de institucionalização, e quando ocorre posicionamento do Supremo Tribunal Federal em caso paradigmático, no julgamento da Ação Direta de Inconstitucionalidade 1.842/RJ, em 2013, até a edição do Estatuto da Metrópole - Lei no 13.089, de 12 de janeiro de 2015, diploma normativo que inaugura uma fase mais recente da chamada institucionalização das regiões metropolitanas.

No Capítulo 2, debruçamo-nos sobre o regime jurídico de tais unidades regionais, iniciando a reflexão contextualizada sob o federalismo cooperativo. Constata-se que, a partir do Estatuto da Metrópole, a região metropolitana passa a ser instrumento de promoção de políticas públicas para a população dos municípios dela integrantes, impondo-se a necessidade da produção de uma regulação urbanística padronizada para promover as funções sociais da cidade-metrópole.

Questões como a interface entre interesse local e interesse comum e sua titularidade, a finalidade e o conceito legal de região metropolitana, o conteúdo e os limites da lei complementar estadual criadora das unidades regionais, bem como o papel e as características do plano de desenvolvimento urbano integrado são analisadas, a partir dos parâmetros normativos da Constituição e da terceira e quarta fases de institucionalização, especialmente o acórdão proferido na ADI 1.842/RJ e o Estatuto da Metrópole.

Considerando os objetivos da República Federativa do Brasil de garantir o desenvolvimento nacional e reduzir as desigualdades sociais e regionais (art. $3^{\circ}$, incisos II e III, Constituição Federal de 1988), e tendo em vista o papel estratégico que as metrópoles têm no desenvolvimento do país, notadamente pela sua centralidade econômica, testamos a hipótese de que a gestão metropolitana pressupõe a conformação de certa estrutura de governança e organização em que a Administração Pública possa atuar e exercer suas atividades, tendo como 
finalidade última a realização das funções públicas de interesse comum para o atendimento das necessidades dos cidadãos.

Nesse sentido, atualmente, além do desafio da exata compreensão do regime jurídico das regiões metropolitanas, após a edição do Estatuto da Metrópole, impõe-se ao Direito a investigação acerca das possibilidades jurídicas de conformação da estrutura de governança e da organização administrativa responsáveis pela integração das funções públicas de interesse comum, desafios aos quais nos propomos.

No Capítulo 3, a abordagem proposta considera a organização estrutural da Administração Pública, que, conforme ensina Fabrício Motta, consiste em buscar, no interior no ordenamento, “a estrutura jurídico-subjetiva mais adequada para a realização de determinados fins" (MOTTA, 2014, p. 37-38). Sem pretender escolher um modelo único, mas propondo a criação de um "sistema metropolitano", analisamos diferentes estruturas jurídicas que possam ser consideradas adequadas para se atender às funções que a Constituição e o Estatuto da Metrópole outorgaram às regiões metropolitanas. Sugerimos atribuições mínimas e comparamos diferentes estruturas institucionais integradoras, que possam resultar da desconcentração (órgãos) e da descentralização (fundação pública, autarquia, empresa pública e sociedade de economia mista) administrativas. Por fim, analisamos o papel dos consórcios públicos na gestão metropolitana.

Algumas ideias apresentadas neste trabalho são resultado do amadurecimento das nossas reflexões a partir de pesquisa realizada junto ao Instituto de Pesquisa Econômica Aplicada (IPEA), no programa Governança Metropolitana, em que a autora elaborou o texto base para a publicação "Comentários ao Estatuto da Metrópole”, que contou com a avaliação de especialistas na área e cujos principais resultados foram apresentados em Oficina de Trabalho realizada na sede do IPEA, em Brasília, em 31 de março de $2017 .^{6}$

\footnotetext{
${ }^{6} \mathrm{Na}$ data de depósito desta dissertação, o livro estava em fase de editoração e tem previsão para lançamento em 2018. Tendo em vista que o estudo realizado foi pioneiro e contou com a participação de vários especialistas, algumas das ideias ali levantadas serão referenciadas nesta dissertação, com referência "no prelo". Os especialistas que analisaram os textos que produzimos foram os seguintes: Alex Ferreira Magalhães, Professor Doutor do Instituto de Pesquisa e Planejamento Urbano e Regional da Universidade Federal do Rio de Janeiro (IPPUR/UFRJ); Benny Schvarsberg, Professor Doutor da Faculdade de Arquitetura e Urbanismo da Universidade de Brasília (UnB); Daniel Augusto Diniz Vila-Nova, Assessor Jurídico do Supremo Tribunal Federal; Daniela Campos Libório, Professora Doutora da Universidade Pontifícia Católica de São Paulo (PUC-SP) e Presidente do Instituto Brasileiro de Direito Urbanístico; Thiago de Azevedo Pinheiro Hoshino, Pesquisador do Instituto Nacional de Ciência e Tecnologia e do Observatório das Metrópoles. Para mais detalhes sobre o Projeto Governança Metropolitana, conferir: <http://www.ipea.gov.br/redeipea/index.php?option=com content\&view=article\&id=97:governanca\%20metrop olitana\&catid=89:projetos-de-pesquisa\&Itemid=206>.
} 
A pesquisa é eminentemente bibliográfica e baseia-se na literatura especializada sobre o tema, especialmente a doutrina jurídica, com a qual dialogamos ao longo de todo o trabalho. Foram investigadas produções científicas nacionais sobre o tema, que serviram de base para a composição do estado da arte dos conceitos apresentados. Obras de autores de outras áreas foram lidas, por se tratar de tema interdisciplinar.

Para melhor conhecimento das questões que envolvem o debate sobre região metropolitana, foram investigadas a legislação brasileira vigentes e aquela que outrora tratou do tema, tais como as Constituições anteriores e a Lei Complementar nº 14/1973.

A pesquisa jurisprudencial resume-se ao Supremo Tribunal Federal, com buscas no sítio eletrônico oficial, por meio da expressão "região metropolitana" e seu equivalente no plural. Não foram analisadas decisões de tribunais estaduais.

Os dados e informações apresentados sobre as "principais regiões metropolitanas" citadas em algumas oportunidades no trabalho referem-se a esse programa do IPEA, mais especificamente à pesquisa realizada em 2013 e divulgada no livro "40 anos de Regiões Metropolitanas no Brasil", 7 com atualizações obtidas na Oficina de Trabalho realizada.

Não são objetos da pesquisa outros instrumentos de cooperação, tais como as regiões de desenvolvimento integrado previstas no art. 43 da Constituição, nem as aglomerações urbanas e microrregiões. Ressalte-se, contudo, que embora se tenha optado por focar nas regiões metropolitanas em razão de sua relevância e pelo fato de haver poucas aglomerações institucionalizadas, as conclusões acerca do regime jurídico são válidas para as aglomerações urbanas, com exceção da definição, única distinção que o Estatuto da Metrópole fez entre tais figuras. As conclusões também são extensíveis às microrregiões com características predominantemente urbanas, tendo em vista a previsão, no art. $1^{\circ}, \S 1^{\circ}, \mathrm{I}$, de que as disposições do Estatuto da Metrópole são aplicáveis a tais unidades regionais. As microrregiões, por seu turno, não foram objeto do Estatuto da Metrópole.

\footnotetext{
${ }^{7}$ IPEA. 40 anos de regiões metropolitanas no Brasil. Organizadores: Marco Aurélio Costa, Isadora Tami Lemos
} Tsukumo. Brasília: Ipea, 2013. 


\section{CONSIDERAÇÕES FINAIS}

Tendo em vista o movimento crescente de metropolização no Brasil, acompanhado do surgimento de problemas de diversas ordens - econômicas, sociais, urbanísticas, ambientais -, buscamos, nesta dissertação, estudar as regiões metropolitanas enquanto instituto jurídico, por meio de uma análise normativa propositiva para a interpretação do ordenamento jurídico acerca do assunto, chegando a conclusões acerca de seu regime jurídico, da sua estrutura de governança e organização administrativa.

Tivemos por propósito investigar os seguintes problemas: qual é o regime jurídico da região metropolitana em face do Estatuto da Metrópole, conjugado com a Constituição e com sua interpretação pelo Supremo Tribunal Federal, especificamente na Ação Direta de Inconstitucionalidade 1.842/RJ? Definido este regime, quais são os requisitos e características que devem ter a estrutura de governança e a organização administrativa para a adequada integração da organização, o planejamento e a execução das funções públicas em comum nas regiões metropolitanas? Quais são as formas jurídicas possíveis para essa integração? Existe uma forma jurídica considerada ideal para a gestão metropolitana?

Vimos, no Capítulo 1, o histórico de institucionalização das regiões metropolitanas, iniciando pela Constituição de 1967, que chamamos de primeiro marco ${ }^{178}$, em que as regiões metropolitanas foram criadas no contexto do projeto nacional desenvolvimentista do Governo Federal à época. Na segunda fase, iniciada a partir da Constituição Federal de 1988, foi possível observar o esvaziamento da questão metropolitana, o que enfraqueceu o processo de institucionalização e dificultou a definição do regime jurídico de tais figuras. Diversos processos políticos ocorridos ao longo da década de 90 permitiram a retomada da agenda cooperativa no país, criando ambiente propício para o surgimento de novas perspectivas teóricas para as regiões metropolitanas.

Demonstramos que, a partir do terceiro e quarto marcos de institucionalização, o ordenamento brasileiro passa a contar com parâmetros normativos mais claros que permitem a definição do regime jurídico das regiões metropolitanas, especialmente porque a interpretação que o STF deu ao art. 25, $\S 3^{\circ}$, da Constituição Federal evidenciou normas que não estavam explícitas no texto. Foi decidido, em linhas gerais, que (i) é competência do Estado-membro instituir regiões metropolitanas, aglomerações urbanas e microrregiões, definindo quais

\footnotetext{
${ }^{178}$ A expressão foi utilizada em trabalho de pesquisa realizado por Moura, Libardi \& Barion (2006) e Edésio Fernandes (2003).
} 
Municípios dela devem fazer parte; (ii) a vinculação dos municípios é compulsória e isso não é incompatível com a autonomia municipal ${ }^{179}$; (iii) a elaboração do plano metropolitano não é de competência exclusiva do Estado e não precisa ser aprovado pela Assembleia Legislativa; (iv) a lei complementar estadual que instituir a unidade regional pode prever um regime especial de exercício de competências municipais, em que os municípios passam a exercer algumas de suas competências em regime colegiado, juntamente com o Estado, no âmbito dos órgãos de governança, sem que isso implique perda de autonomia; (v) a região metropolitana deve ser gerida por um colegiado, do qual participam todos os Municípios e o Estado, de forma equilibrada, não necessariamente paritária, evitando-se a concentração do poder decisório no âmbito de um único ente; (vi) o poder concedente e o titular das funções e do serviço público de interesse comum na região metropolitana é o colegiado.

A partir da quarta fase, inaugurada com a edição do Estatuto da Metrópole - Lei $\mathrm{n}^{\circ}$ 13.089/2015, foram esclarecidas questões que ainda causavam dúvidas, tais como os critérios técnicos para a instituição de regiões metropolitanas, a conceituação de elementos centrais para a gestão metropolitana - tais como "governança interfederativa" e "funções públicas de interesse comum" -, e a definição do plano de desenvolvimento urbano integrado como instrumento básico de desenvolvimento urbano integrado.

Em face disso, concluímos que que o gargalo da institucionalização comumente chamado pelos estudiosos especializados como o "elo perdido" da gestão metropolitana foi, do ponto de vista jurídico-institucional, gradualmente superado por meio do fortalecimento do marco normativo para tais unidades regionais, especialmente a partir da terceira e da quarta fases de institucionalização.

No contexto atual de institucionalização, quanto ao regime jurídico, no Capítulo 2 analisamos, inicialmente, a inserção da questão metropolitana no escopo dos estudos sobre federalismo, ressaltando a adoção do federalismo cooperativa pela Constituição e sua evolução ao longo da segunda fase. Propusemos que as regiões metropolitanas devem ser interpretadas à luz do federalismo cooperativo, notadamente no que diz respeito às competências comuns.

A titularidade das funções públicas de interesse comum é do colegiado formado pelo Estado e pelos Municípios, tendo como pressuposto a ausência de concentração de poder em um único ente. A finalidade precípua da instituição da região metropolitana é garantir a unidade das políticas públicas e ações correlatas na perspectiva das funções públicas de interesse comum. A conjugação da regra constitucional com o novo marco legal eleva a região

\footnotetext{
${ }^{179}$ Consoante visto nos capítulos anteriores, a questão da compulsoriedade já era pacífica nos precedentes do STF: cf. ADI 1.841/RJ, Rel. Min. Carlos Velloso; ADI 796/ES, Rel. Min. Néri da Silveira.
} 
metropolitana à condição de promotora de políticas públicas para as populações metropolitanas, devendo se aparelhar administrativamente para tanto.

Com o advento da Lei $n^{\circ}$ 13.089/2015, a região metropolitana passa a ter definição legal relacionada a critérios técnicos que levam em consideração fatores urbanísticos, geográficos, sociais e econômicos, adotados pelo IBGE. Essa previsão concilia o descolamento entre a região metropolitana tomado enquanto fenômeno urbanístico-espacial e enquanto instituto jurídico.

O legislador estadual está adstrito a limites constitucionais e legais para instituir as regiões metropolitanas por meio de lei complementar. Como conteúdo mínimo, a lei deve prever (art. $5^{\circ}$, Lei $\mathrm{n}^{\circ} 13.089 / 2015$ ): os Municípios que integram a unidade territorial urbana (inc. I); os campos funcionais ou funções públicas de interesse comum que justificam a instituição da unidade territorial urbana (inc. II); a conformação da estrutura de governança interfederativa, incluindo a organização administrativa e o sistema integrado de alocação de recursos e de prestação de contas (inc. III); e os meios de controle social da organização, do planejamento e da execução de funções públicas de interesse comum (inc. IV).

Quanto à estrutura de governança, entendemos que a lei também deverá trazer elementos mínimos acerca da estrutura institucional integradora, tendo em vista que a estrutura orgânica dotada de poderes específicos se mostra indispensável para a execução dos objetivos que são cometidos às regiões metropolitanas. Em especial, ressaltamos atribuições específicas para integrar as funções públicas, bem como dotá-la de poder normativo para o controle das atividades e serviços de interesse regional.

Não há incompatibilidade entre o caráter compulsório das regiões metropolitanas, pela leitura sistemática e teleológica da Constituição, sendo que a governança bem estruturada pode permitir maior eficácia no cumprimento das missões constitucionais dos Municípios. Na prática, a gestão metropolitana dependerá em grande medida da construção de consensos, razão pela qual a estrutura de governança deve ser bem construída.

O planejamento metropolitano, instrumentado juridicamente pelo plano de desenvolvimento urbano integrado, atrai a aplicação do Direito Urbanístico. Para que seja efetivo, deve contar com elementos de integração, notadamente a compatibilização de outros instrumentos de planejamento, tais como os planos plurianuais dos entes que integram a região metropolitana. A previsão legal de que o plano será elaborado pela Assembleia Legislativa pode gerar questionamentos, sendo recomendável buscar consensos no âmbito da estrutura de governança, de modo a evitar a desnaturação do plano na Assembleia ou eventual judicialização da matéria que impeça a executoriedade da ordenação metropolitana. 
No Capítulo 3, investigamos os parâmetros normativos referentes à conformação da estrutura de governança e à organização administrativa para atendimento das questões metropolitanas. A partir da análise da Constituição, do acórdão da ADI 1.842/RJ e de outros julgados do STF sobre o tema, bem como da interpretação do Estatuto da Metrópole, concluímos que o regime jurídico caracterizado no Capítulo 2, a partir da autorização constitucional do $\S 3^{\circ}$ do art. 25, bem como das disposições do Estatuto da Metrópole, tem como consequência lógica a imperatividade da instrumentalização necessária à realização de suas finalidades, justificadoras de sua própria criação. Em outras palavras, a região metropolitana é caracterizada por uma organização administrativa que seja capaz de abarcar a estrutura de governança (art. $8^{\circ}$, Estatuto da Metrópole) e a estrutura integradora das FPICs, dotada de autonomia política, administrativa e financeira.

Além disso, das disposições constitucionais, do Estatuto da Metrópole e da jurisprudência do STF sobre a estrutura das regiões metropolitanas mapeamos os seguintes parâmetros normativos para a conformação da estrutura de governança e da organização administrativa: a governança deve ser interfederativa, ou seja, compartilhada entre Estado e Municípios; a representação da sociedade civil na estrutura de governança é obrigatória, em atendimento ao princípio da participação e da gestão democrática da cidade; cabe ao Estado a conformação básica da estrutura de governança, a partir das peculiaridades e das necessidades específicas da região metropolitana que se pretende instituir.

A estrutura, para deter autonomia política e financeira, deve ter personalidade jurídica própria. A personalização também é condição para o exercício das competências que consideramos essenciais para a efetiva integração das FPICs: competência para celebrar contratos, convênios e acordos de qualquer natureza, inclusive para contratar e ser o poder concedente, permitente ou autorizante dos serviços públicos de interesse comum; competência para exercer o poder de polícia; e competência normativa para controlar a gestão das FPICs.

A competência para contratar é indispensável para que a estrutura institucional criada no âmbito da região metropolitana possa realizar o principal objetivo para o qual foi criada, a integração das FPICs. Esta capacidade, aliás, decorre da sua personalidade jurídica, porém é mais seguro juridicamente que esta possibilidade esteja expressamente prevista na lei complementar estadual e demais normas que tratarem da instituição.

Outra atribuição instrumental indispensável para a realização dos objetivos da criação da região metropolitana refere-se ao exercício do poder de polícia - ou atividade ordenadora pela estrutura institucional responsável pela integração das funções públicas de interesse comum, inclusive visando à adequada gestão metropolitana a integração do exercício das 
atividades urbanísticas. Tais atividades, contudo, devem se limitar aos interesses comuns, não podendo representar extensão aos assuntos locais correspondentes à atuação municipal.

A capacidade normativa mostra-se também essencial para a integração. Sem a capacidade de editar atos cogentes, que devam ser observados e obedecidos por todos os entes integrantes da entidade metropolitana, a gestão seguirá sendo rarefeita e desarticulada. A lei complementar estadual deve prever expressamente o poder normativo e regulamentar na perspectiva da integração do planejamento, da organização e da execução das funções públicas de interesse comum.

Quanto aos formatos jurídicos possíveis, foram analisados os modelos de órgão (decorrentes da desconcentração), bem como da autarquia, sociedade de economia mista e empresa pública (resultantes da descentralização administrativa).

Os órgãos públicos, por serem desprovidos de personalidade jurídica, não se apresentam como instrumentos adequados para a estrutura integradora. Contudo, a articulação de órgãos já em funcionamento nos entes que compõem a região metropolitana pode ser estimulada pela "entidade metropolitana" com o objetivo de atender a assuntos de interesse comum.

As autarquias apresentam como vantagens principais a autonomia administrativa, financeira e política, bem como a imunidade tributária, além de ser figura já conhecida pela Administração Pública para o exercício de funções especializadas. Sendo criada por lei, para que seja de fato interfederativa, será necessário que todos os Municípios editem leis autorizando a sua criação, a exemplo do que ocorre no caso da construção de consórcios públicos. Além de desnaturar o caráter compulsório das regiões metropolitanas, este modelo pode engessar as relações entre a entidade metropolitana e os parceiros privados, por estar integralmente sujeita ao regime público.

Os modelos empresariais podem ser utilizados para a integração de uma função pública específica, em atuação setorial, especificamente para prestação de serviços públicos (direta ou indiretamente), por deterem maior autonomia e flexibilidade em relação às autarquias. Uma sugestão é a instituição de empresa interfederativa, cujos acionistas sejam os Municípios e o Estado. Esse modelo dependerá de negociações e, para garantir maior segurança jurídica, de delegação expressa do exercício de competências dos entes para a estatal. Embora haja precedentes judiciais positivos, pode haver questionamento quanto ao exercício de poder de polícia por tais empresas. A utilização deste modelo impõe a existência de um espaço de governança central, desvinculado de forma direta das atividades de cunho empresarial.

Os consórcios públicos não se confundem com as regiões metropolitanas, sendo instrumentos de desenvolvimento urbano-integrado (art. $9^{\circ}$, VI, Lei ${ }^{\circ} 13.089 / 2015$ ). Por terem 
regime jurídico consolidado e por já serem utilizados para a integração de determinados serviços comuns em várias regiões metropolitanas do país, sua conjugação com a estrutura de governança metropolitana pode gerar bons resultados na gestão metropolitana. Por se tratar de forma de gestão que resulta da associação voluntária dos entes, dependerá da construção de consensos entre os entes para o efetivo funcionamento.

Não existe um modelo único de estrutura aplicável a todas as regiões metropolitanas (FARIAS \& CORREIA, 2014; SPINK et al, 2009; COSTA \& TSUKUMO, 2013), porém os parâmetros mínimos identificados devem estar presentes na estruturação de qualquer dos modelos jurídicos. A escolha pelo formato jurídico será feita, em princípio, com base no poder discricionário do Estado, devendo se basear na conveniência e oportunidade e levando em consideração as vantagens e desvantagens institucionais apresentadas para cada uma das figuras analisadas. Deve, em qualquer caso, ser embasada por estudos prévios, de viabilidade econômica e financeira, de condicionantes institucionais e de mapeamento das capacidades estatais já existentes, relativos às FPICs. $\mathrm{O}$ formato adequado deve considerar a complexidade e as peculiaridades das FPIC se o constante dinamismo da governança metropolitana.

Em qualquer caso, é imperioso que estrutura integradora esteja sujeita às deliberações da entidade metropolitana central, evitando-se a articulação e a fragmentação atualmente constatada.

Em face disso, concluímos que a lei complementar estadual deve prever, no mínimo, os campos funcionais ou funções públicas de interesse comum que justificam a instituição da unidade territorial urbana e a conformação da estrutura de governança interfederativa, incluindo a organização administrativa e o sistema integrado de alocação de recursos e de prestação de contas (art. $5^{\circ}$, II e III). O legislador estadual deverá equilibrar a previsão dos contornos gerais da estrutura de governança - ou de todo o sistema metropolitano -, incluindo o arranjo institucional básico, com competências e outros elementos instrumentais mínimos, sem esgotar a matéria e sem definir todas as diretrizes de atuação na perspectiva das FPICs, delegando o poder decisório à estrutura de governança.

Não há vedação legal para que todas as atividades - gestão e integração da execução das FPICs - estejam reunidas numa mesma estrutura jurídica, e o Estatuto da Metrópole até parece apontar para a criação de uma "super entidade metropolitana", porém parece-nos inconveniente a existência de uma estrutura jurídica única e gigante que abarque as atribuições de governança e de deliberações de todas as funções públicas de interesse comum juntamente com as funções de execução e operação das políticas públicas e ações de interesse comum.

Estruturas administrativas mais especializadas tendem a ser mais eficientes (essa é a 
própria lógica do princípio da especialidade) e assim podem se apresentar mais adequadas para o atendimento de políticas públicas tecnicamente complexas ou de setores muito específicos.

O retrato da gestão metropolitana no Brasil reflete a existência de iniciativas setoriais e desarticuladas entre si, sendo essa gestão marcada pela fragmentação institucional, com tendências de setorialização e isolamento entre cada setor/campo funcional (COSTA \& TSUKUMO, 2013). Os relatórios de gestão metropolitana de todas as quinze regiões metropolitanas analisadas pelo IPEA neste estudo evidenciam a desarticulação setorial, isto é, em geral há uma articulação isolada exclusiva para cada uma das funções públicas de interesse comum $^{180}$ e a instância de governança não funciona como espaço de gestão central.

As diferenças dos setores correlatos a cada função pública de interesse comum, ou a cada campo funcional, gravam a gestão metropolitana de complexidade típicas de um ente governamental, porém sabemos que a Constituição não pretendeu a criação de novo ente. A conciliação entre a complexidade das atribuições dessa "superestrutura" metropolitana e os diferentes arranjos operacionais necessários pode ser a criação de um "sistema metropolitano", em que diferentes estruturas setoriais convivam, configurando "subsistemas", unidos sob as diretrizes de uma governança central - a entidade metropolitana. Em cada sistema poderia haver uma estrutura administrativa específica, ou poderiam ser aproveitadas as estruturas já existentes dos entes, para aqueles temas que são transversais a todos os outros (como meio ambiente, por exemplo).

Peter Spink et al (2009, p. 472) ressaltam a dificuldade do trabalho integrado e sugere a concentração da atenção em estratégias monotemáticas, criando agências para questões específicas e desenvolvendo mecanismos de governança de maneira similar.

Sugerimos, no caso, que o Estado, ao criar a região metropolitana, por meio da lei complementar estadual, foque na estruturação da governança interfederativa, garantindo-se que o espaço decisório seja de fato compartilhado, onde se possa definir a respeito da organização administrativa necessária à integração de determinada FPIC.

A construção de um "sistema metropolitano" com a conjugação de diferentes estruturas administrativas apresenta-se como o caminho mais adequado para a integração das funções públicas de interesse comum. A construção deste sistema é deveras complexa e dependerá sempre das peculiaridades, inclusive históricas, de cada região metropolitana, bem como das capacidades estatais já existentes.

180 O IPEA aponta as cinco principais: transporte, saneamento (água, esgoto, drenagem), resíduos sólidos, habitação e uso do solo. No estudo, a função "resíduos sólidos" foi separada da função "saneamento" porque os arranjos da gestão normalmente os separam desta forma e se desenvolvem de forma destacada. 
Neste trabalho, concluímos que a efetiva gestão metropolitana depende da articulação entre as diferentes estruturas de gestão atuantes em cada setor, e especialmente da delimitação precisa das especificidades de cada setor (diferenciando-se, por exemplo, aqueles setores que contam com tarifa e os que não contam, os que tendem a ser deficitários, etc.).

Buscou-se contribuir com a construção desse "sistema metropolitano" partir da identificação das possibilidades jurídicas para instituição de estruturas administrativas mais adequadas para a gestão da região metropolitana, à luz das finalidades constitucionais que justificam sua instituição e tendo em vista o regime jurídico das regiões metropolitanas, apontando características que possam se apresentar vantajosas ou desvantajosas no âmbito de um sistema plural de gestão metropolitana. O detalhamento desse sistema metropolitano certamente será objeto de pesquisa futura.

Importante ressaltar que, embora tenha a lei complementar estadual, com fundamento no art. $25, \S 3^{\circ}$, da Constituição, o condão de condicionar o exercício da competência dos entes federados, é recomendável que, visando à redução de riscos de judicialização e de questionamentos, haja delegação expressa dos Municípios acerca do exercício das competências necessárias à integração de cada FPIC, seja no âmbito da estrutura de governança, seja por meio de lei autorizativa da criação de uma estrutura administrativa específica. É fato que a mera edição da lei complementar estadual não será suficiente para resolver os gargalos de gestão verificados nas regiões metropolitanas, sendo necessário um esforço de articulação entre os entes, o que certamente demandará negociações prévias.

Entendemos que a estruturação da governança de forma equilibrada, com observância dos parâmetros aventados no Capítulo 3, permitindo a manifestação de todos os entes integrantes da região metropolitana, a despeito de ser suficiente do ponto de vista jurídico para justificar a integração da FPIC (com as delegações de competência que se fizerem necessárias), pode não ser suficiente do ponto de vista político. Somente o caso concreto poderá mostrar qual o caminho que permite maior consensualidade, segurança jurídica e estabilidade para o modelo jurídico de integração. 


\section{REFERÊNCIAS}

ABRUCIO, Fernando Luiz. Descentralização: Pacto Federativo. Cadernos Escola Nacional de Administração Pública - ENAP, Brasília, n. 1, p. 16-33, 1993.

ALOCHIO, Luís Henrique Antunes. O problema da concessão de serviços públicos em regiões metropolitanas: (re)pensando um tema relevante. Interesse Público - IP, Belo Horizonte, v. 5, n. 242004.20 Disponível em: <http://www.bidforum.com.br/bid/PDI0006.aspx?pdiCntd=50650>. Acesso em: 19 jan. 2017.

Plano Diretor Urbano e Estatuto da Cidade - Medidas Cautelares E Moratórias Urbanísticas. Belo Horizonte: Fórum, 2010.

ALVES, Alaôr Caffé. O uso do solo metropolitano: disciplinamento e controle. Conflitos e competências. In: MARTINS, Ives Gandra da Silva; COLASUONNO, Miguel (Coords.). Estudos sobre o amanhã: regiões metropolitanas. São Paulo: Resenha Universitária, 1978. p.15-39.

Planejamento Metropolitano e autonomia municipal do direito brasileiro. São Paulo: Baushatsky, 1981.

Regiões Metropolitanas, Aglomerados Urbanos e Microrregiões: novas dimensões constitucionais da organização do Estado brasileiro. In: FIGUEIREDO, Guilherme José Purvin (Org.) Temas de Direito Ambiental e Urbanístico. São Paulo: Max Limonad, 1998. p. 13-55.

APPARECIDO JUNIOR, José Antônio. Direito Urbanístico Aplicado: os caminhos da eficiência jurídica nos projetos urbanísticos. Curitiba: Juruá, 2017.

ARAÚJO, Edmir Netto. Curso de Direito Administrativo. 4. ed. São Paulo: Saraiva, 2009.

ARRETCHE, Marta. Federalismo e políticas sociais no Brasil: problemas de coordenação e autonomia. São Paulo em Perspectiva. [online], v.18, n. 2, 2004, p.17-26. Disponível em: <http://www.scielo.br/pdf/spp/v18n2/a03v18n2.pdf>. Acesso em 07 jul. 2017.

ATALIBA, Geraldo. República e Constituição. 2. ed. São Paulo, Malheiros, 2007.

AZEVEDO, Eurico de Andrade. A região metropolitana no Brasil e seu regime jurídico. In: MARTINS, Ives Gandra da Silva; COLASUONNO, Miguel (Coords.) Estudos sobre o amanhã: regiões metropolitanas. São Paulo: Resenha Universitária, 1978. p. 123-161.

Instituição das Regiões Metropolitanas no Brasil. Revista Brasileira dos Municípios,

Rio de Janeiro, v. 20, n. 79/80, 1967. p.121-129. Disponível em: $<$ http://biblioteca.ibge.gov.br/visualizacao/monografias/GEBIS\%20-

\%20RJ/RBM/RBM_n79_80\%20jul_dez1967.pdf>. Acesso em 05 jul. 2017.

AZEVEDO, Eurico de Andrade; MENDES, Raul Armando. Princípios para instituição de regiões metropolitanas. Revista Justitia, São Paulo, v. 57, n. 68, p. 79-97, 1967. Disponível em: 〈http://www.revistajustitia.com.br/links/edicao.php?ID=073>. Acesso em: 01 mai. 2017. 
AZEVEDO, Sérgio de; GUIA, Virgínia Rennó Mares. Arranjos Institucionais para a Gestão Metropolitana. Relatório de pesquisa - Observatório das Metrópoles: território, coesão e governança democrática. Rio de Janeiro: UFRJ/CNPq, 2009. Disponível em: <http://www.observatoriodasmetropoles.ufrj.br/relatorio_arranjos_gestao_metropolitana.pdf $>$ . Acesso em 7 jul. 2017.

AZEVEDO, Sérgio de; GUIA, Virgínia R. dos Mares. Reforma do Estado e federalismo: os desafios da governança metropolitana. In: RIBEIRO, Luiz César de Queiroz (Coord.). O futuro das metrópoles: desigualdades e governabilidade. Rio de Janeiro: Revan, 2000. p. 525-549.

BAINES, Christian; SOUZA, Emerson Goulart Caetano de; GIALDI, Odete Carmem; SCHURGELIES, Vinicius. Fortalecimento das Relações Metropolitanas: o caso de São Paulo. 2013. 90f. Dissertação (Mestrado em Gestão e Políticas Públicas) - Escola de Administração de Empresas de São Paulo, Fundação Getúlio Vargas, São Paulo, 2013.

BALBIM, Renato; BECKER, Maria Fernanda; COSTA, Marco Aurélio; MATTEO, Miguel. Desafios Contemporâneos na gestão das Regiões Metropolitanas. In: LINHARES, Paulo de Tarso F.; MENDES, Constantino C.; LASSANCE, Antonio (Orgs.). Federalismo à brasileira: questões para discussão. Volume 8 (Diálogos para o Desenvolvimento). Brasília: Ipea, 2012. p. 113-143.

Disponível

em:

<http://www.ipea.gov.br/portal/images/stories/PDFs/livros/livros/livro_federalismoabrasileira _v08.pdf $>$. Último acesso em 6 ago. 2017.

BANDEIRA DE MELlO, Celso Antônio. Curso de Direito Administrativo. 31. ed. São Paulo: Malheiros, 2013.

. Natureza e regime jurídico das autarquias. São Paulo: RT, 1968.

BARROSO, Luís Roberto. Saneamento básico: competências constitucionais da União, Estados e Municípios. Revista Eletrônica de Direito Administrativo Econômico (REDAE), Salvador, n. 11, p. 1-21, 2007. Disponível em: <http://www.direitodoestado.com/revista/REDAE-11-AGOSTO-2007-

LUIS\%20ROBERTO\%20BARROSO.pdf>. Acesso em 08 set. 2017.

BERCOVICI, Gilberto. Dilemas do Estado Federal Brasileiro. Porto Alegre: Livraria do Advogado, 2004.

BERCOVICI, Gilberto; SIQUEIRA NETO, José Francisco. O Artigo 23 da Constituição de 1988 e as Competências Comuns. Revista Brasileira de Estudos Constitucionais, Belo Horizonte, v. 6, p. 49-65, 2008.

BOBBIO, Norberto. Da Estrutura à Função: novos estudos de teoria do direito. São Paulo: Manole, 2007.

BONAVIDES, Paulo. Curso de Direito Constitucional. 30. ed. São Paulo: Malheiros, 2015.

BRUNO, Reinaldo Moreira. Regiões metropolitanas. Posição no Cenário Constitucional, Competência e Financiamento de suas Atividades no Estado Brasileiro. Curitiba: Juruá, 2016. 
BUCCI, Maria Paula Dallari. Gestão associada de serviços públicos e regiões metropolitanas. In: WAGNER JÚNIOR, Luiz Guilherme da Costa (Org.). Direito Público: Estudos em homenagem ao Professor Adílson Abreu Dallari. Belo Horizonte: Del Rey, 2004. p. 551-559.

Gestão Democrática da Cidade. In: DALLARI, Adilson Abreu; FERRAZ, Sérgio (Coords.). Estatuto da Cidade. 4. ed. São Paulo: Malheiros, 2010. p. 335-354.

. Políticas Públicas e Direito Administrativo. Revista Trimestral de Direito Público, São Paulo, n. 13, p. 134-144, 1996.

CARVALHO, André Castro. Direito da Infraestrutura: Perspectiva Pública - São Paulo: QuartierLatin, 2014.

CARVALHO FILHO, José dos Santos. Manual de Direito Administrativo. São Paulo: Atlas, 2017.

Plano Diretor e Inconsciência Urbanística. In: MARQUES NETO, Floriano de Azevedo; ALMEIDA, Fernando Dias Menezes de; NOHARA, Irene Patrícia; MARRARA, Thiago. (Orgs.). Direito e Administração Pública. Estudos em Homenagem a Maria Sylvia Zanella Di Pietro. São Paulo: Atlas, 2013. p. 596-612.

CASTRO, José Nilo de. Direito Municipal Positivo. Belo Horizonte: Del Rey, 1991.

COELHO, Fábio Ulhoa. Curso de Direito Civil. Vol. 1. São Paulo: Saraiva, 2003. 2010 .

Curso de Direito Comercial. Vol. 2: direito de empresa. 14. Ed. São Paulo: Saraiva,

COSTA, Marco Aurélio; MARGUTI, Bárbara de Oliveira (Orgs.). Funções Públicas de Interesse Comum nas Metrópoles Brasileiras: transportes, saneamento básico e uso do solo. Série Rede Ipea. Projeto Governança Metropolitana no Brasil, v. 2. Brasília: Ipea, 2014.

Série Rede Ipea. Projeto Governança Metropolitana no Brasil, v. 4. No prelo.

COSTA, Marco Aurélio; PANTOJA, Igor; MARGUTI, Bárbara de Oliveira (Orgs.). Relatos e Estudos de Caso da Gestão Metropolitana no Brasil. Série Rede Ipea. Projeto Governança Metropolitana no Brasil, v. 3. Brasília: Ipea, 2014. Disponível em: $<$ http://www.ipea.gov.br/portal/index.php?option=com_content\&view=article\&id=24032>.

Última data de acesso em 01 ago. 2017

COSTA, Marco Aurélio; TSUKUMO, Isadora Tami Lemos (Orgs.). 40 anos de regiões metropolitanas no Brasil. Série Rede Ipea. Projeto Governança Metropolitana no Brasil, v. 1. Brasília: Ipea, 2013.

DALLARI, Adilson de Abreu. Subsídios para a criação imediata de entidades metropolitanas. Revista de Direito Público, São Paulo, 13, p. 309-311, 1970a. 1970b.

Uso do solo metropolitano. Revista de Direito Público, São Paulo, 14, p. 285-295, 
DALLARI, Dalmo de Abreu. O Estado Federal. São Paulo: Editora Brasiliense, 1986.

. Elementos de Teoria Geral do Estado. 33. ed. São Paulo: Saraiva, 2017.

O futuro do Estado. 2. ed. São Paulo: Saraiva, 2007.

. O Município Brasileiro. Serra Negra: 1959.

. O que é Participação Política. São Paulo: Brasiliense, 1985.

Parecer proferido sobre a Lei Complementar $n^{\circ} 41$, de 13 de junho de 2014, do

Estado da Bahia, na ADI 5155/BA, do Supremo Tribunal Federal. São Paulo, 17 de novembro de 2014.

DI PIETRO, Maria Sylvia Zanella. Direito Administrativo. 30. ed. São Paulo: Forense, 2017.

. Poder de Polícia em Matéria Urbanística. In: MINISTÉRIO PÚBLICO DO ESTADO DE SÃO PAULO. Temas de Direito Administrativo. São Paulo: Ministério Público de São Paulo/Imprensa Oficial, 1999. p. 23-38.

ESTORNINHO, Maria João. A fuga para o direito privado: contributo para o estudo da atividade de direito privado da administração pública. 2. Reimpr. Coimbra: Almedina, 2009.

FARIAS, Talden; CORREIA, Arícia Fernandes. Regionalismo como uma nova perspectiva para o federalismo brasileiro: o leading case relativo à Região Metropolitana do Rio de Janeiro. Revista Magister de Direito Ambiental e Urbanístico, Porto Alegre, v. 9, n. 51, p. 5-39, 2014.

FERNANDES, Antônio Sérgio Araújo. A Gestão Metropolitana no Brasil em perspectiva comparada: os casos das regiões metropolitanas de Salvador e Belo Horizonte. Cadernos Adenauer: Municípios e Estados: experiências com arranjos cooperativos, Rio de Janeiro, ano XII, n. 4, p. 219-234, 2011.

FERNANDES, Edésio. A nova ordem jurídico-urbanística no Brasil. Direito urbanístico. Estudos Brasileiros e Internacionais. Belo Horizonte: Del Rey/Lincoln Institute, 2006.

.Gestão metropolitana. Cadernos da Escola do Legislativo, Belo Horizonte, v. 7, n. 12, p, 65-99, 2004.

O elo perdido: o desafio da gestão metropolitana. Fórum de Direito Urbano e Ambiental - FDUA, Belo Horizonte, ano 2, n. 12, 2003. Disponível em: <http://www.bidforum.com.br/bidLogin.aspx?ReturnUrl=\%2fPDI0006.aspx\%3fpdiCntd\%3d 11042\&pdiCntd=11042>. Acesso em: 01 ago. 2017.

. Reforma urbana e reforma jurídica no Brasil: duas questões para reflexão. Fórum de Direito Urbano e Ambiental - FDUA, Belo Horizonte, ano 6, n. 34, jul./ago. 2007. Disponível em:

<http://www.bidforum.com.br/bidLogin.aspx?ReturnUrl=\%2fbid\%2fPDI0006.aspx\%3fpdiCn

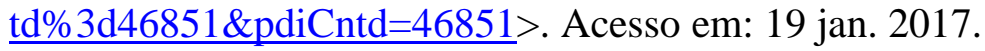


FERRAZ JUNIOR, Tércio Sampaio. Introdução ao Estudo de Direito. 4. ed. São Paulo: Atlas, 2003.

FERRAZ, Sérgio. As regiões metropolitanas no Direito Brasileiro. Revista de Direito Público, São Paulo, 37/38, p. 19-24, 1976.

FERREIRA FILHO, Manoel Gonçalves. Curso de Direito Constitucional. 18. ed. São Paulo: Saraiva, 1990.

Do Processo Legislativo. 6. ed. São Paulo: Saraiva, 2007.

FIRKOWSKI, Olga L. C. Metrópoles e Regiões metropolitanas no Brasil: conciliação ou divórcio? In: FURTADO, Bernardo Alves; KRAUSE, Cleandro; DE FRANÇA, Karla Christina Batista. (Eds.). Território metropolitano, políticas municipais: por soluções conjuntas de problemas urbanos no âmbito metropolitano. Brasília: Ipea, 2013. p. 21-51.

FRANZESE, Cibele. Federalismo cooperativo no Brasil: da Constituição de 1988 aos sistemas de políticas públicas. 2010. 210 f. Tese (Doutorado em Administração Pública e Governo) - Escola de Administração de Empresas de São Paulo, Fundação Getúlio Vargas, São Paulo, 2010.

GARCIA, Fernando Couto. Financiamento nas Regiões Metropolitanas. In: Memória da Oficina Nacional "Adequação dos Arranjos de Governança Metropolitana ao Estatuto da Metrópole e Subsídios à Elaboração dos Planos de Desenvolvimento Urbano Integrado (PDUI)", 16-17 mai. 2016. Brasília: Ipea, 2016. p. 8.

GOUVÊA, Ronaldo Guimarães. A questão metropolitana no Brasil. São Paulo: Fundação Getúlio Vargas, 2005.

Autonomia municipal em regiões metropolitanas: as questões administrativa e política. Anais do XXIII International Congress of the Latin American Studies Association LASA2001.Washington, D.C. 2001. p. 1-20. Disponível em: <http://lasa.international.pitt.edu/Lasa2001/GuimaraesGouveaRonaldo.pdf $>$. Acesso em 08 dez. 2016

GRAU, Eros. Direito Urbano. Regiões metropolitanas, Solo criado, Zoneamento e Controle Ambiental, Projeto de Lei de Desenvolvimento Urbano. São Paulo: Revista dos Tribunais, 1983.

Regiões metropolitanas: regime jurídico. São Paulo: José Bushatsky, 1974.

GRINOVER, Ada Pelegrini; PIMENTEL, Darci Fernandes. Regiões Administrativas intraestaduais. Proposta de administração descentralizada intergovernamental (Estados e Municípios). Revista de Direito Público, 41-42/239, 1977. In: DI PIETRO, Maria Sylvia Zanella; SUNDFELD, Carlos Ari (Orgs.). Doutrinas Essenciais - Direito Administrativo. Vol. 1. São Paulo: Editora Revista dos Tribunais, 2012. p. 1189-1206.

GUIMARÃES, Nathália Arruda. Regiões metropolitanas: aspectos jurídicos. Revista Jus Navigandi, Teresina, ano 9, n. 273, 2004. Disponível em: 〈https://jus.com.br/artigos/5050〉. Acesso em: 26 ago. 2017. 
HAMILTON, Alexander; JAY, Jonh; MADISON, James. O Federalista. Trad. Hiltomar Martins de Oliveira. Belo Horizonte: Líder, 2003.

HORBACH, Carlos Bastide. Comentários aos arts. 25 a 27 da Lei n ${ }^{\circ}$ 10.257/2001. In: MEDAUAR, Odete; ALMEIDA, Fernando Dias Menezes de (Coords.). Estatuto da Cidade: Lei 10.257, de 10.07.2001, Comentários. 2 ed. São Paulo: Revista dos Tribunais, 2004, p. 187200.

HORTA, Raul Machado. Direito Constitucional Brasileiro e as regiões metropolitanas. Revista de Informação Legislativa, Brasília, v. 12, n. 46, p. 33-42, 1975.

IBGE - Instituto Brasileiro de Geografia e Estatística. Arranjos populacionais e concentrações urbanas no Brasil. 2. ed. Rio de Janeiro: IBGE, 2016. Disponível em: <https://biblioteca.ibge.gov.br/visualizacao/livros/liv99700.pdf>. Acesso em 12 mai. 2017.

- Censo demográfico 1940-2010. Até 1970 dados extraídos de: Estatísticas do século XX. Rio de Janeiro: IBGE, 2007 no Anuário Estatístico do Brasil - 1981, vol. 42.

Censo Demográfico 2010. Disponível em: <https://censo2010.ibge.gov.br/> Último acesso em 01 set. 2017.

Regiões de Influência das Cidades - REGIC: 2007. Rio de Janeiro: IBGE, 2008. Disponível em: 〈https://biblioteca.ibge.gov.br/visualizacao/livros/liv40677.pdf>. Último acesso em 09 set. 2017.

IPEA - Instituto de Pesquisa Econômica Aplicada. I Atlas da Vulnerabilidade Social e Regiões Metropolitanas Brasileiras. 2016. Disponível em: <http://ivs.ipea.gov.br/index.php/pt/>. Último acesso em 12 out. 2017.

IPEA - Instituto de Planejamento Econômico e Social. A Institucionalização de Regiões Metropolitanas. Rio de Janeiro: Ministério do Planejamento e Coordenação Geral/IPEA, 1969. Disponível em: 〈http://repositorio.ipea.gov.br/handle/11058/7860〉. Último acesso em 12 set. 2017.

JUSTEN FILHO, Marçal. Curso de Direito Administrativo. 12. ed. São Paulo: Revista dos Tribunais, 2016.

KLINK, JeroenJohannes. Novas Governanças para as áreas metropolitanas: O panorama internacional e as perspectivas para o caso brasileiro. Cadernos Metrópole, São Paulo, v. 11, n. 22, p. 415-433, 2009.

KRELL, Andreas J. Leis de normas gerais, regulamentação do poder executivo e cooperação intergovernamental em termos de reforma federativa. Belo Horizonte: Fórum, 2008.

LIBÓRIO, Daniela Campos. Competências Urbanísticas. In: DALLARI, Adilson Abreu; FERRAZ, Sérgio (Coord.). Estatuto da Cidade. 4. ed. São Paulo: Malheiros, 2010. p. 61-69.

LIBÓRIO, Daniela Campos. Elementos de Direito Urbanístico. Barueri: Manole, 2004. 
. Urbanismo e Meio ambiente. In: DALLARI, Adilson de Abreu; NASCIMENTO, Carlos Valder do; MARTINS, Ives Gandra da Silva (Coord.). Tratado de Direito Administrativo. v. 2. São Paulo: Saraiva, 2013. p. 674-692.

LIMA. Fabrício Muriana. Algumas condições de possibilidade de participação na revisão do Plano Diretor Paulistano (2013-2014). 2017. 103 f. Dissertação (Mestrado Profissional em Mudança Social e Participação Política) - Escola de Artes, Ciências e Humanidades, Universidade de São Paulo. São Paulo, 2017.

LOPES, Alberto. Gestão metropolitana no Brasil: da Coerção Simétrica ao Voluntarismo sem Modelo, em busca de responsabilidade política com resultados. In SILVA, Caria Antonia, FREIRE, Désirée Guichard, OLIVEIRA, Floriano José Godinho (Orgs.). Metrópole: governo, sociedade e território. Rio de Janeiro: DP\&A/Faperj, 2006. p. 137-155.

MACHADO, Alberto Vellozo et al. O fetiche metropolitano: colocando as ideias em ordem com o Estatuto da Metrópole. Revista Jurídica do Ministério Público do Estado do Paraná, Curitiba, ano 3, n. 5, p. 27-41, 2016. Disponível em: <http://www.urbanismo.mppr.mp.br/arquivos/File/O_fetiche_metropolitano.pdf>. Acesso em 02 ago. 2017.

MACHADO, Alberto Velozzo; SERRANO JÚNIOR, Odoné; HOSHINO, Thiago de Azevedo Pinheiro. A ADI 1.842/RJ e a Lei 13.089/2015: novos paradigmas para as Regiões Metropolitanas brasileiras? Revista Jurídica do Ministério Público do Estado do Paraná, Curitiba, ano 2, n. 2, p. 408-424, 2015. Disponível em: <http://www2.mppr.mp.br/imprensa/revista_mppr_2.pdf $>$. Acesso em 05 mai. 2017.

MACHADO, Gustavo Gomes. Gestão metropolitana e autonomia municipal. Belo Horizonte: Ed. PUC-Minas, 2009.

MACHADO, Gustavo Gomes; PIRES, Maria Coeli Simões. Os consórcios públicos: aplicação na gestão de regiões metropolitanas, aglomerações urbanas e microrregiões. In: PIRES, Maria Coeli Simões; BARBOSA, Maria Elisa Braz (Coords.). Consórcios públicos: instrumentos do federalismo cooperativo. Belo Horizonte: Fórum, 2008. p. 405-476.

MAGALHÃES, Fernanda (Ed.). Regiões Metropolitanas no Brasil - um paradoxo de desafios e oportunidades. Banco Interamericano de Desenvolvimento. Nova Iorque: Banco Interamericano de Desenvolvimento, 2011.

MARQUES NETO, Floriano Azevedo. Agências Reguladoras Independentes. Belo Horizonte: Fórum, 2009.

Regulação estatal e interesses públicos. São Paulo: Malheiros, 2002.

Fundamentos e Conceituação das PPP. In: MARQUES NETO, Floriano de Azevedo; SCHIRATO, Vitor Rhein (Coords.). Estudos sobre a Lei das parcerias públicoprivadas. Belo Horizonte: Fórum, 2011. p. 13-29.

MARTINS, Ives Gandra da Silva; COLASUONNO, Miguel. Estudos sobre o amanhã: regiões metropolitanas. São Paulo: Resenha Universitária, 1978. 
MEDAUAR, Odete. Direito Administrativo Moderno. 18. ed. rev. atual. São Paulo: Revista dos Tribunais, 2014.

O direito administrativo em evolução. 2. ed. rev. atual. e ampl. São Paulo: Revista dos Tribunais, 2003.

MEIRELLES, Hely Lopes. Direito Municipal Brasileiro. 2. ed. v. 1. São Paulo: Revista dos Tribunais, 1964.

. Direito Municipal Brasileiro. 6. ed. São Paulo: Malheiros, 1993.

MELO, Marcus André. Municipalismo, Nation-building e a modernização do Estado no Brasil. Revista Brasileira de Ciências Sociais, n. 23, p. 83-100, 1993. Disponível em: <http://www.anpocs.org.br/portal/publicacoes/rbcs_00_23/rbcs23_07.htm>. Acesso em abr. 2017.

MENCIO, Mariana. Consórcios públicos e regiões metropolitanas. In: NUNES JÚNIOR, Vidal Serrano et al (Coords.). Enciclopédia Jurídica da PUC-SP. Tomo: Direito Administrativo e Constitucional. São Paulo: Pontifícia Universidade Católica de São Paulo, 2017. Disponível em: <https://enciclopediajuridica.pucsp.br/verbete/61/edicao-1/consorcios-publicos-e-regiaometropolitana Acesso em 18/10/2017>. Acesso em 02 out. 2017.

. O Regime Jurídico do Plano Diretor das Regiões Metropolitanas. 2013. 469 f. Tese (Doutorado em Direito) - Faculdade de Direito, Pontifícia Universidade Católica de São Paulo, São Paulo. 2013.

MENDES, Gilmar Ferreira. Regiões metropolitanas e saneamento público. In: MENEZES DE ALMEIDA, Fernando Dias; MARQUES NETO, Floriano de Azevedo; MIGUEL, Luiz Felipe Hadlich; SCHIRATO, Vitor Rhein (Coords.). Direito Público em Evolução: Estudos em homenagem à Professora Odete Medauar. Belo Horizonte: Fórum, 2013. p. 685-698.

MENEZES DE ALMEIDA, Fernando Dias. Contrato Administrativo. São Paulo: Quartier Latin, 2012.

MODESTO, Paulo. Notas para um debate sobre o princípio da eficiência. Revista do Serviço Público, Brasília, v. 51, n. 2, p. 105-120, 2000. Disponível em: <https://revista.enap.gov.br/index.php/RSP/article/view/328/334>. Acesso em: 09 set. 2017.

. Região metropolitana, estado e autonomia municipal: a governança interfederativa em questão. Revista Brasileira de Direito Público - RBDP, Belo Horizonte, ano 14, n. 53, p. 127-136, 2016.

MONEBHURRUN, Nitish. Metodologia Jurídica. Técnicas para argumentar em textos jurídicos. São Paulo: Saraiva, 2012.

MORAND-DEVILLER, Jacqueline. Cours de droit administratif. 11. ed. Paris: Montchrestien, 2009. 
MOREIRA NETO, Diogo Figueiredo. Poder Concedente para o abastecimento de água. Revista de Direito da Associação dos Procuradores do Novo Estado do Rio de Janeiro, Rio de Janeiro, n.1, p. 23-33, 1999.

MOREIRA, Felipe Lélis. Constitucionalidade da regulação do uso do solo metropolitano à luz da Lei $\mathrm{n}^{\circ}$ 13.089, de 12 de janeiro de 2015, que institui o Estatuto da Metrópole. Revista Brasileira de Direito Municipal - RBDM, Belo Horizonte, ano 16, n. 58, p. 13-25, 2015.

MOREIRA, Mariana. A história do Estatuto da Cidade. In: DALLARI, Adilson Abreu; FERRAZ, Sérgio (Coord.). Estatuto da Cidade. 4. ed. São Paulo: Malheiros, 2010. p. 27-43.

MOTTA, Fabrício. Função normativa da Administração Pública. Belo Horizonte: Fórum, 2007.

Tratado de Direito Administrativo: administração pública e servidores públicos. São Paulo: Editora Revista dos Tribunais, 2014.

MOURA, Rosa; HOSHINO, Thiago de Azevedo Pinheiro. Estatuto da metrópole: enfim, aprovado! Mas o que oferece à metropolização brasileira? 2015. Disponível em: 〈http://www.observatoriodasmetropoles.net/download/estatuto_metropole_artigo_rosa.pdf $>$.

Acesso em 12 ago. 2017.

MOURA, Rosa; LIBARDI, Diócles; BARION, Maria Isabel. Institucionalização de Regiões Metropolitanas: qual o sentido? Revista Paranaense de Desenvolvimento. Curitiba, n. 111, p. 129-143, 2006. Disponível em: 〈http://www.ipardes.pr.gov.br/ojs/index.php/revistaparanaense/article/view/64>. Acesso em 23 set. 2017.

NEGREIROS, Rovena. Gestão metropolitana: um desafio que se renova. Revista Paranaense de Desenvolvimento, Curitiba, n. 100, p. 81-92, 2001. Disponível em: <http://www.ipardes.gov.br/pdf/revista_PR/100/rovena.pdf $>$. Acesso em 25 abr. 2017.

NOHARA, Irene Patrícia. Consensualidade e gestão democrática do interesse público no Direito Administrativo contemporâneo. Interesse Público, Belo Horizonte, v. 15, n. 78, 2013.

ONU - Organização das Nações Unidas. Nova Agenda Urbana. 2016. Disponível em: $<$ http://habitat3.org/wp-content/uploads/NUA-Portuguese-Angola.pdf $>$. Acesso em: 30 set. 2017.

PEREZ, Marcos Augusto. Administração pública democrática: institutos de participação popular na Administração Pública. Belo Horizonte: Fórum, 2004.

PINTO, Henrique Motta. A autarquização das empresas estatais na jurisprudência do STF: um obstáculo para as reformas na Administração Pública. Cadernos gestão pública e cidadania, São Paulo, v. 15, n. 57, 15-233, 2010.

PINTO, Vitor Carvalho. Cidades conurbadas e a Constituição: modelos institucionais para as regiões metropolitanas. Cadernos Aslegis, Brasília, n. 34, p, 193-208, 2008. Disponível em: <http://bd.camara.gov.br/bd/handle/bdcamara/11193>. Acesso em 04 mai. 2017. 
Direito Urbanístico: Plano Diretor e Direito de Propriedade. São Paulo: Revista dos Tribunais. 4. ed. 2014.

PINTO JUNIOR, Mario Engler. A estrutura da administração pública indireta e o relacionamento do Estado com a companhia controlada. Revista de Direito Público da Economia RDPE, Belo Horizonte, ano 7, n. 28, 2009. Disponível em: <http://www.bidforum.com.br/bidLogin.aspx?ReturnUrl=\%2fbid\%2fPDI0006.aspx\%3fpdiCn td\%3d64264\&pdiCntd=64264>. Acesso em: 30 set. 2017.

PIRES, Maria Coeli Simões. A Institucionalização das Regiões Metropolitanas e no Novo Modelo de Federalismo Brasileiro. Belo Horizonte: Editora da Assembleia Legislativa do Estado de Minas Gerais, 1986.

PIRES, Roberto Rocha C. (Org.). Efetividade das instituições participativas no Brasil: estratégias de avaliação. Volume 7 (Diálogos para o desenvolvimento). Brasília: Ipea, 2011. Disponível em: <http://www.ipea.gov.br/portal/images/stories/PDFs/livros/livro_dialogosdesenvol07.pdf>. Acesso em 12 ago. 2017.

REIS FILHO, Nestor Goulart. Urbanização e planejamento no Brasil, 1960-1983. Cadernos de Pesquisa do LAP (USP), São Paulo, Caderno 11, 1996.

RHODES, Roderick Arthur William. The New Governance: Governing Without Government. Political Studies, v. 44, n. 4, p. 652-667, 1996.

RIBEIRO, Luiz Cesar de Queiroz; SANTOS, Orlando Alves dos; RODRIGUES, Juciano Martins. Estatuto da Metrópole: o que esperar? Avanços, limites e desafios. 2015. Disponível em: 〈https://goo.gl/ZYpmGB>. Acesso em: 01 ago. 2017.

RIBEIRO, Luiz César de Queiroz; MOURA, Rosa, DELGADO, Paulo, SILVA, Érica Tavares da (Coords.). Níveis de integração dos municípios brasileiros em RMs, RIDEs e AUs à dinâmica da metropolização. Relatório de pesquisa - Observatório das Metrópoles. Rio de Janeiro: INCT/CNPq/CAPES/FAPERJ, 2012. Disponível em: <http://www.observatoriodasmetropoles.net/download/relatorio_integracao.pdf $>$ Último acesso em 12 ago. 2017.

RIBEIRO, Wladimir António. A autonomia municipal como princípio constitucional. In: CNM - Confederação Nacional dos Municípios. V Revista Jurídica da Confederação Nacional de Municípios. Brasília: CNM, 2017. p. 70-85.

Julgamento do STF sobre regiões metropolitanas, aglomerações urbanas e microrregiões: uma derrota dos municípios. In: CNM - Confederação Nacional dos Municípios. II Revista Jurídica da Confederação Nacional de Municípios. Brasília: CNM, 2013. p. 8894.

RIBEIRO, Wladimir Antônio; COSTA, Silvano Silvério. Dos porões à luz do dia. Um itinerário dos aspectos jurídico-institucionais do saneamento no Brasil. In: HELLER, Léo. CASTRO, José Esteban (Orgs.). Política pública e gestão de serviços de saneamento. Rio de Janeiro: Fiocruz; Belo Horizonte: Fórum, 2013. p. 467-501. 
RODRIGUES, Juciano Martins. Unidades Territoriais Urbanas no Brasil: Regiões Metropolitanas, Regiões Integradas de Desenvolvimento Econômico e Aglomerações Urbanas em 2015. 2015. Disponível em: <http://www.observatoriodasmetropoles.net/images/abook_file/relatorio_unidadesurbanas201 5.pdf>. Último acesso em 10 out. 2017.

ROLNIK, Raquel; SOMEKH, Nadia. Governar as metrópoles: dilemas da descentralização. In: RIBEIRO, Luiz César de Queiroz (Org.). Metrópoles: entre a coesão e a fragmentação, a cooperação e o conflito. São Paulo: Editora Fundação Perseu Abramo, 2004. p. 111-124.

SANO, Hironobu; ABRUCIO, Fernando Luiz. Reforma do Estado, Organizações Sociais e Accountability: o caso paulista. In: Anais do XXVII EnANPAD, Atibaia-SP, 2003. Disponível em: 〈https://goo.gl/64DDQi >. Acesso em: 16 ago. 2017.

SANTOS, Marcela de Oliveira; RIBEIRO, Wladimir António. A intermunicipalidade e as regiões metropolitanas no Direito Brasileiro. In: CNM - Confederação Nacional dos Municípios. III Revista Jurídica da Confederação Nacional de Municípios. Brasília: CNM, 2015. p. 244-265.

SANTOS JÚNIOR, Orlando Alves dos; MONTANDON, Daniel Todtmann (Orgs.). Os planos diretores municipais pós Estatuto da Cidade: balanço crítico e perspectivas. Rio de Janeiro: Letra Capital: Observatório das Cidades: IPPUR/UFRJ, 2011.

SERRANO, Paulo Estevam Alves Pinto. Região Metropolitana e seu regime constitucional. São Paulo: Verbatim, 2009.

. Regiões Metropolitanas. In: DALLARI, Adilson de Abreu; NASCIMENTO, Carlos Valder do; MARTINS, Ives Gandra da Silva (Coords.). Tratado de Direito Administrativo. v. 2. São Paulo: Saraiva, 2013. p. 600-642.

SILVA, Almiro do Couto e. Região Metropolitana: Fundação criada por Estado e Municípios. Revista de Direito Público, São Paulo, ano VII, n. 28, p. 42-51, 1974.

SILVA, Caria Antonia, FREIRE, Désirée Guichard, OLIVEIRA, Floriano José Godinho (Orgs.). Metrópole: governo, sociedade e território. Rio de Janeiro: DP\&A/Faperj, 2006.

SILVA, Hendrick Pinheiro da. Planejamento e controle: uma reflexão sobre ética. Revista Contas Abertas - Revista Técnica do Tribunal de Contas de Mato Grosso do Sul, Campo Grande, v. 3, n. 3, p. 23-27, 2017.

SILVA, José Afonso da. Curso de Direito Constitucional Positivo. São Paulo: Malheiros, 2005.

SOUZA, Celina. Constitucional Engineering in Brasil: The Politics of Federalism and Decentralization. London: Macmillan; New York: St. Martin's Press, 1997.

SOUZA, Celina. Federalismo e Descentralização na Constituição de 1988: processo decisório, conflitos e alianças. Dados - Revista de Ciências Sociais, Rio de Janeiro, v. 44, n. 3, p. 513$560,2001$. 
SPINK, Peter K.; TEIXEIRA, Marco A. C.; CLEMENTE, Roberta. Governança, governo ou gestão: o caminho das ações metropolitanas. Cadernos Metrópole, São Paulo, v. 11, n. 22, p. 453-476, 2009. Disponível em: <http://revistas.pucsp.br/index.php/metropole/article/view/5943/4296>. Acesso em 02 ago. 2017.

SUNDFELD, Carlos Ari. Direito Administrativo Ordenador. São Paulo: Malheiros, 1997.

SUNDFELD, Carlos Ari. O Estatuto da Cidade e suas diretrizes gerais. In: DALLARI, Adilson Abreu; FERRAZ, Sérgio (Coords.). Estatuto da Cidade. 4. ed. São Paulo: Malheiros, 2010. p. 44-60.

TÁCITO, Caio. O retorno do pêndulo: Serviço público e empresa privada. O exemplo brasileiro. Revista de Direito Administrativo, Rio de Janeiro, v. 202, p. 1-10,1995. Disponível em: 〈http://bibliotecadigital.fgv.br/ojs/index.php/rda/article/view/46612 > Acesso em: 31 jul. 2017.

. Saneamento básico - região metropolitana. Competência estadual (parecer). Revista de Direito Administrativo, Rio de Janeiro, v. 213, p. 323-328, 1998.

TEIXEIRA, Ana Carolina Wanderley. Região metropolitana: instituição e gestão contemporânea; dimensão participativa. Belo Horizonte: Ed. Forum, 2009.

TEMER, Michel. Elementos de Direito Constitucional. Malheiros: São Paulo, 2008. 